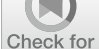

updates

Cite as

Nano-Micro Lett.

(2021) 13:178

Received: 26 April 2021

Accepted: 24 June 2021

Published online: 17 August 2021

(C) Crown 2021

\section{Electrolyte/Structure-Dependent Cocktail Mediation Enabling High-Rate/Low-Plateau Metal Sulfide Anodes for Sodium Storage}

\author{
Yongchao Tang ${ }^{1,2}$, Yue Wei ${ }^{3}$, Anthony F. Hollenkamp ${ }^{2}$, Mustafa Musameh ${ }^{2}$, \\ Aaron Seeber ${ }^{2}$, Tao Jin ${ }^{2,4}$, Xin Pan ${ }^{1}$, Han Zhang ${ }^{1}$, Yanan Hou ${ }^{1}$, Zongbin Zhao ${ }^{1}$, \\ Xiaojuan $\mathrm{Hao}^{2 凶}$, Jieshan Qiu ${ }^{5}$, Chunyi Zhi ${ }^{6}$
}

\title{
HIGHLIGHTS
}

- Nano-dispersed $\mathrm{SnS}_{2}$ and $\mathrm{CoS}_{2}$ phases endow CSC anode with electrolyte/structure-dependent cocktail mediation effect, showing superior rate capability and evidently lowered charge plateau compared with $\mathrm{CoS}_{2}$ and $\mathrm{SnS}_{2} / \mathrm{CoS}_{2}$ mixture.

- Alternative electrochemical processes between nano-dispersed different metal sulfides and $\mathrm{Na}^{+}$carriers effectively overcome intrinsic flaws of monometallic sulfide, responsible for the lowered charge plateau of CSC.

- As-assembled $\mathrm{CSC} / / \mathrm{Na}_{1.5} \mathrm{VPO}_{4.8} \mathrm{~F}_{0.7}$ full-cell shows high-rate capability, and high discharge plateau up to $2.57 \mathrm{~V}$, which is comparable to that with alloy-type anodes.

ABSTRACT As promising anodes for sodium-ion batteries, metal sulfides ubiquitously suffer from low-rate and high-plateau issues, greatly hindering their application in full-cells. Herein, exemplifying carbon nanotubes (CNTs)stringed metal sulfides superstructure (CSC) assembled by nano-dispersed $\mathrm{SnS}_{2}$ and $\mathrm{CoS}_{2}$ phases, cocktail mediation effect similar to that of high-entropy materials is initially studied in ether-based electrolyte to solve the challenges. The high nano-dispersity of metal sulfides in CSC anode underlies the cocktail-like mediation effect, enabling the circumvention of intrinsic drawbacks of different metal sulfides. By utilizing ether-based electrolyte, the reversibility of metal sulfides is greatly improved, sustaining a long-life effectivity of cocktail-like mediation. As such, CSC effectively overcomes low-rate flaw of $\mathrm{SnS}_{2}$ and highplateau demerit of $\mathrm{CoS}_{2}$, simultaneously realizes a high rate and a low plateau. In half-cells, CSC delivers an ultrahigh-rate capability of $327.6 \mathrm{mAh} \mathrm{g}^{-1}$ anode at $20 \mathrm{~A} \mathrm{~g}^{-1}$, far outperforming those of monometallic sulfides $\left(\mathrm{SnS}_{2}, \mathrm{CoS}_{2}\right)$ and their mixtures. Compared with $\mathrm{CoS}_{2}$ phase and $\mathrm{SnS}_{2} / \mathrm{CoS}_{2}$ mixture, CSC shows

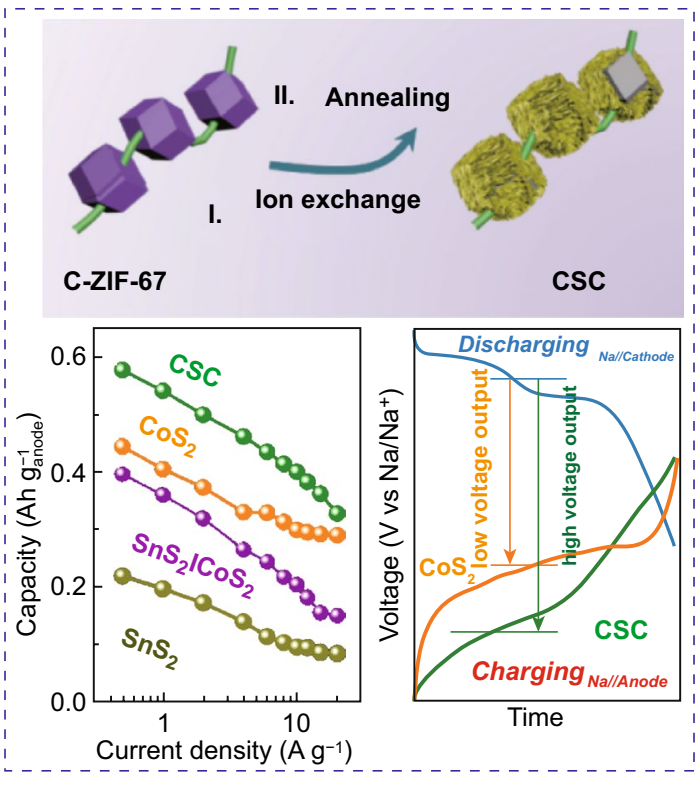

Yongchao Tang and Yue Wei author have contributed equally to this work.

$\bowtie$ Anthony F. Hollenkamp, Tony.Hollenkamp@csiro.au; Xiaojuan Hao, Xiaojuan.Hao@csiro.au; Jieshan Qiu, qiujs@mail.buct.edu.cn

1 State Key Lab of Fine Chemicals, Liaoning Key Lab for Energy Materials and Chemical Engineering, School of Chemical Engineering, Dalian University of Technology, Dalian 116024, P. R. China

2 Manufacturing, Commonwealth Scientific and Industrial Research Organization (CSIRO), Clayton, VIC 3168, Australia

3 State Key Laboratory of Fine Chemicals, School of Chemical Engineering, Dalian University of Technology, Dalian 116024, P. R. China

4 School of Resources and Environment Engineering, Shandong Agriculture and Engineering University, Jinan 250100, P. R. China

5 College of Chemical Engineering, Beijing University of Chemical Technology, Beijing 100029, China

6 Department of Materials Science and Engineering, City University of Hong Kong, 83 Tat Chee Avenue, Hong Kong, P. R. China 
remarkably lowered average charge voltage up to $c a$. $0.62 \mathrm{~V}$. As-assembled CSC//Na ${ }_{1.5} \mathrm{VPO}_{4.8} \mathrm{~F}_{0.7}$ full-cell shows a good rate capability $\left(0.05 \sim 1.0 \mathrm{~A} \mathrm{~g}^{-1}, 120.3 \mathrm{mAh} \mathrm{g}^{-1}\right.$ electrode at $\left.0.05 \mathrm{~A} \mathrm{~g}^{-1}\right)$ and a high average discharge voltage up to $2.57 \mathrm{~V}$, comparable to full-cells with alloy-type anodes. Kinetics analysis verifies that the cocktail-like mediation effect largely boosts the charge transfer and ionic diffusion in CSC, compared with single phase and mixed phases. Further mechanism study reveals that alternative and complementary electrochemical processes between nano-dispersed $\mathrm{SnS}_{2}$ and $\mathrm{CoS}_{2}$ phases are responsible for the lowered charge voltage of CSC. This electrolyte/ structure-dependent cocktail-like mediation effect effectively enhances the practicability of metal sulfide anodes, which will boost the development of high-rate/-voltage sodium-ion full batteries.

KEYWORDS Metal sulfide anode; Rate capability; Voltage plateau; Cocktail mediation effect; Sodium-ion batteries

\section{Introduction}

With the merits of high capacity and low cost, metal sulfides have been recognized as promising anode materials for sodium-ion batteries (SIBs) [1, 2]. However, most metal sulfide anodes examined to date exhibit poor high-rate performance and/or voltage behavior that trends rapidly to relatively high values. The result is full-cells that only operate well at a low rate $\left(\leq 0.5 \mathrm{~A} \mathrm{~g}^{-1}\right.$ electrode $)$ and maintain average output voltages typically $\leq 2 \mathrm{~V} \_$ENREF_6 [3-8]. At this level of performance, such cells are only slightly better than a number of advantages in energy density over aqueous batteries (e.g., zinc batteries) but noncomparable safety to the latter [9-12]. Thus far, many studies on metal sulfide anodes still focus on the enhancement in reversible capacity, rate capability, and cyclability in half-cells. Even few studies concerning the properties of metal sulfide anodes in fullcells, most of them only roughly evaluate the performance of full-cells based on anodes instead of total electrodes. This could result in certain intrinsic flaws of metal sulfide anodes underrated [10]. Therefore, from the perspective of full-cell, to solve the low-rate and high-plateau issues of metal sulfide anodes is crucial for the development of high-performance full-cells (Scheme 1a).

Different metal sulfides usually show electrolyte/structure-dependent electrochemical properties, offering valuable inspiration to rationally design new architectures and investigate their properties in proper electrolyte [3, 13, 14]. Compared with ester-based electrolytes, ether-based electrolytes can effectively inhibit3 the shuttle effect of polysulfides in situ formed during discharge/charge processes, thus more beneficial to obtain reversible properties of metal sulfides [1, 13, 15]. Ferromagnetic metal (Fe, Co, Ni, etc.) sulfides (FMSs) are very promising conversion-reaction anode materials widely studied for SIBs [16-19]. Compared with conventional hard carbon or red phosphorous anodes, FMS anodes can display ultrahigh-rate capability $(\geq 20 \mathrm{~A}$ $\mathrm{g}^{-1}$ ) in ether-based electrolyte, holding a great promise in SIBs (Scheme 1b) [20-22]. However, FMS anode usually suffers from severe voltage hysteresis and high plateau $\left(\sim 1.9 \mathrm{~V}\right.$ vs $\left.\mathrm{Na} / \mathrm{Na}^{+}\right)$, largely lowering the discharge plateau of full-cells (Scheme 1c). From this point, mono-component FMSs seem to be difficult to meet the requirements for high-performance full-cells. So far, despite many relevant studies, most of them are inclined to ignoring the severe intrinsic flaws of FMSs, emphasizing to enhance capacity and cyclability. By contrast, another series of metal ( $\mathrm{Sn}, \mathrm{Sb}$, $\mathrm{Bi}$, etc.) sulfides (AMSs) with conversion/alloying-reaction mechanisms can show acceptable voltage hysteresis and relatively lower voltage plateau [23-30]. However, these AMSs always suffer from severe volume change during discharge/charge processes, resulting in poor rate capability and cyclability in ester-based electrolytes (Scheme 1b). Owing to latent catalysis over the decomposition of certain ether, such AMSs remain scarcely investigated in ether-based electrolyte [31, 32]. Encouragingly, by utilizing fluorine-containing sodium salt in ether solvents as electrolyte, the undesirable catalysis of AMSs can be effectively suppressed to allow a stable battery operation [33, 34]. The good compatibility enables the investigation of electrochemical properties of FMS/AMS composites in ether-based electrolytes. In the multi-component metal sulfide anodes, each component functions as active material and mutually compete. Thus, the electrochemical behaviors of multi-component metal sulfides are comprehensive results from individual component. Given that exotic properties beyond rule-of-mixtures (cocktail-like mediation effect) in multi-component highentropy nano-systems [35, 36], to construct new superstructures assembled by nano-dispersed FMSs and AMSs and to study their properties in ether-based elctrolytes, could be 
(a)

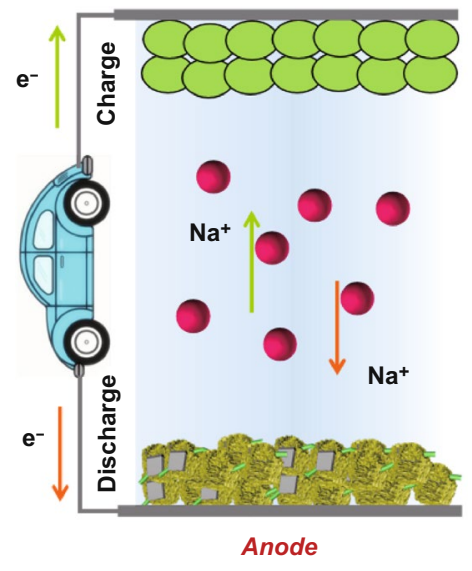

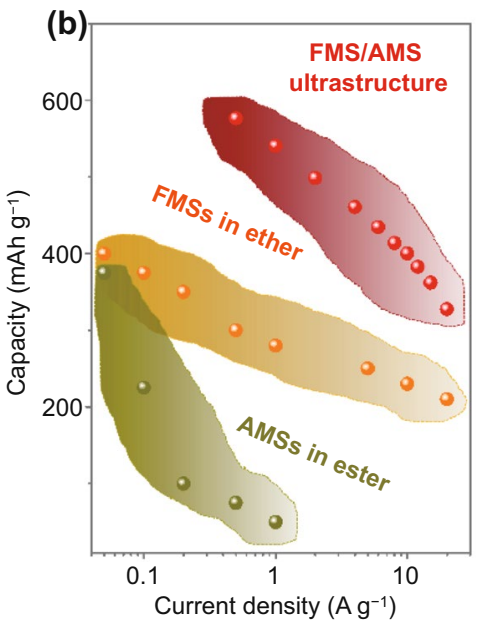

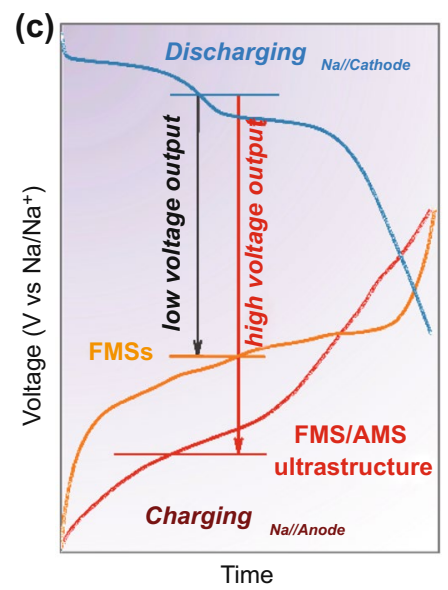

Scheme 1 a Prototype of full-cells. b Rate capability comparison of typical metal sulfide anodes in half-cells. c Discharge plateau comparison in full-cells with different metal sulfide anodes showing the merits of FMS/AMS ultrastructure

an effective strategy toward high-performance full-cells. Additionally, the poor conductivity of most metal sulfides makes them essential to further combine with highly conductive carbon materials. Such combination can endow rational architectures with fast ion/electron transfer, which is conducive to obtaining satisfactory electrochemical properties [13, 37-39]. So far, despite some studies pertaining to FMS/AMS composites, the certain agglomeration or phase separation between FMS and AMS remains unsatisfactory to investigate their comprehensive impact. Additionally, such studies mostly involved the electrochemical properties of FMS/AMS composites in carbonate-based electrolytes [40-42]. Thus, to study the voltage behavior of metal sulfide composites in ether-based electrolytes will provide a new perspective to pursue desired sodium storage properties.

Herein, CNTs-stringed metal sulfides superstructure anode assembled by nano-dispersed $\mathrm{SnS}_{2}$ and $\mathrm{CoS}_{2}$ phases (CSC, C: CNT; S: $\mathrm{SnS}_{2}$; C: $\mathrm{CoS}_{2}$ ) is engineered to combine the merits of FMS- and AMS-type anode materials, aiming at simultaneously solving the dual-problems of poor rate capability/output-voltage characteristics (Scheme 1b-c). The highly nano-dispersed metal sulfides in CSC show remarkable cocktail-like mediation effect, effectively circumventing intrinsic drawbacks of different metal sulfides. The etherbased electrolyte greatly enhances the reversibility of metal sulfides, which can inhibit the aggregation of homogenous metal sulfides, enabling a long-life effectivity of cocktaillike mediation. In half-cells, CSC delivers an ultrahigh-rate capability of $327.6 \mathrm{mAh} \mathrm{g}^{-1}$ at $20 \mathrm{~A} \mathrm{~g}^{-1}$, showing remarkably lowered average charge plateau up to $0.62 \mathrm{~V}$ vs Na/ $\mathrm{Na}^{+}$, compared with $\mathrm{CoS}_{2}$ phase and $\mathrm{SnS}_{2} / \mathrm{CoS}_{2}$ mixture. The asassembled $\mathrm{CSC} / / \mathrm{Na}_{1.5} \mathrm{VPO}_{4.8} \mathrm{~F}_{0.7}$ full-cell shows a good rate capability $\left(0.05 \sim 1.0 \mathrm{~A} \mathrm{~g}^{-1}, 120.3 \mathrm{mAh} \mathrm{g}^{-1}\right.$ electrode at 0.05 $\mathrm{A} \mathrm{g}^{-1}$ ) and a high average discharge voltage up to $2.57 \mathrm{~V}$, comparable to full-cells with alloy-type anodes. Kinetics and mechanism studies reveal that the cocktail mediation effect largely boosts the charge transfer and ionic diffusion in CSC; along the diffusion direction of $\mathrm{Na}^{+}$carriers, alternative and complementary electrochemical processes between different nano-dispersed metal sulfides $\left(\mathrm{SnS}_{2}, \mathrm{CoS}_{2}\right)$ and $\mathrm{Na}^{+}$carriers are responsible for the lowered average charge plateau of CSC. This exhibited cocktail-like mediation effect evidently improves the practicability of metal sulfide anodes, which will boost the development of high-rate/-voltage sodium-ion full batteries.

\section{Results and Discussion}

\subsection{Materials Preparation and Characterization}

The CSC was initially obtained by ion-exchange reaction between thiostannate $\left(\mathrm{Sn}_{\mathrm{x}} \mathrm{S}_{\mathrm{y}}{ }^{\mathrm{n}}\right)$ and cobalt-based zeolitic imidazolate framework (ZIF-67) followed by annealing treatment (Fig. 1a). For an enhanced conductivity of the resulting CSC, the ZIF-67 particles (C-ZIF-67) are connected together ('stringed') by a network of CNTs (Fig. 
S1). $\mathrm{Sn}^{119}$ NMR spectroscopy reveals that several tetravalent thiostannate species $\left(\mathrm{SnS}_{3}{ }^{2-}, \mathrm{SnS}_{4}{ }^{4-}\right.$, and $\left.\mathrm{Sn}_{2} \mathrm{~S}_{6}{ }^{4-}\right)$ exist in solution and these are referred to collectively as ' $\mathrm{Sn}_{\mathrm{x}} \mathrm{S}_{\mathrm{y}}{ }^{\mathrm{n}-}$ ', (Fig. S2) [43]. Within the ion-exchange process, $\mathrm{Co}^{2+}$ in ZIF-67 reacts rapidly with $\mathrm{Sn}_{\mathrm{x}} \mathrm{S}_{\mathrm{y}}{ }^{\mathrm{n}-}$ species, forming a unique superstructure comprised of nano-dispersed $\mathrm{CoS}_{2}$ and $\mathrm{SnS}_{2}$ phases. The overall reaction follows Eq. (1):

$\mathrm{Sn}_{x} \mathrm{~S}_{y}^{n-}+\mathrm{Co}^{2+} \rightarrow \mathrm{SnS}_{2}+\mathrm{CoS}_{2}(1 \leq x \leq 2, \quad 3 \leq y \leq 6,2 \leq n \leq 4)$
As shown in Fig. 1b, X-ray diffraction (XRD) patterns exhibit the diffraction peaks of $\mathrm{CoS}_{2}$ (PDF No. 00-411471), $\mathrm{SnS}_{2}$ (PDF No. 00-23-0677), and carbon, verifying their presence in the CSC. Compared with standard phase, the reflection for the $\left(\begin{array}{lll}0 & 0 & 1\end{array}\right)$ plane of $\mathrm{SnS}_{2}$ registers a slight shift toward lower angles, implying an expanded interlayer spacing $[14,44]$. The expanded interlayer spacing could be associated with the use of thiostannate precursor and low-temperature ion-exchange process. The ion-exchange reaction of thiostannate with ZIF-67 typically occurs at $-5{ }^{\circ} \mathrm{C}$ in $1 \mathrm{~h}$, where fast reassembly of $\mathrm{SnS}_{2}$ results in
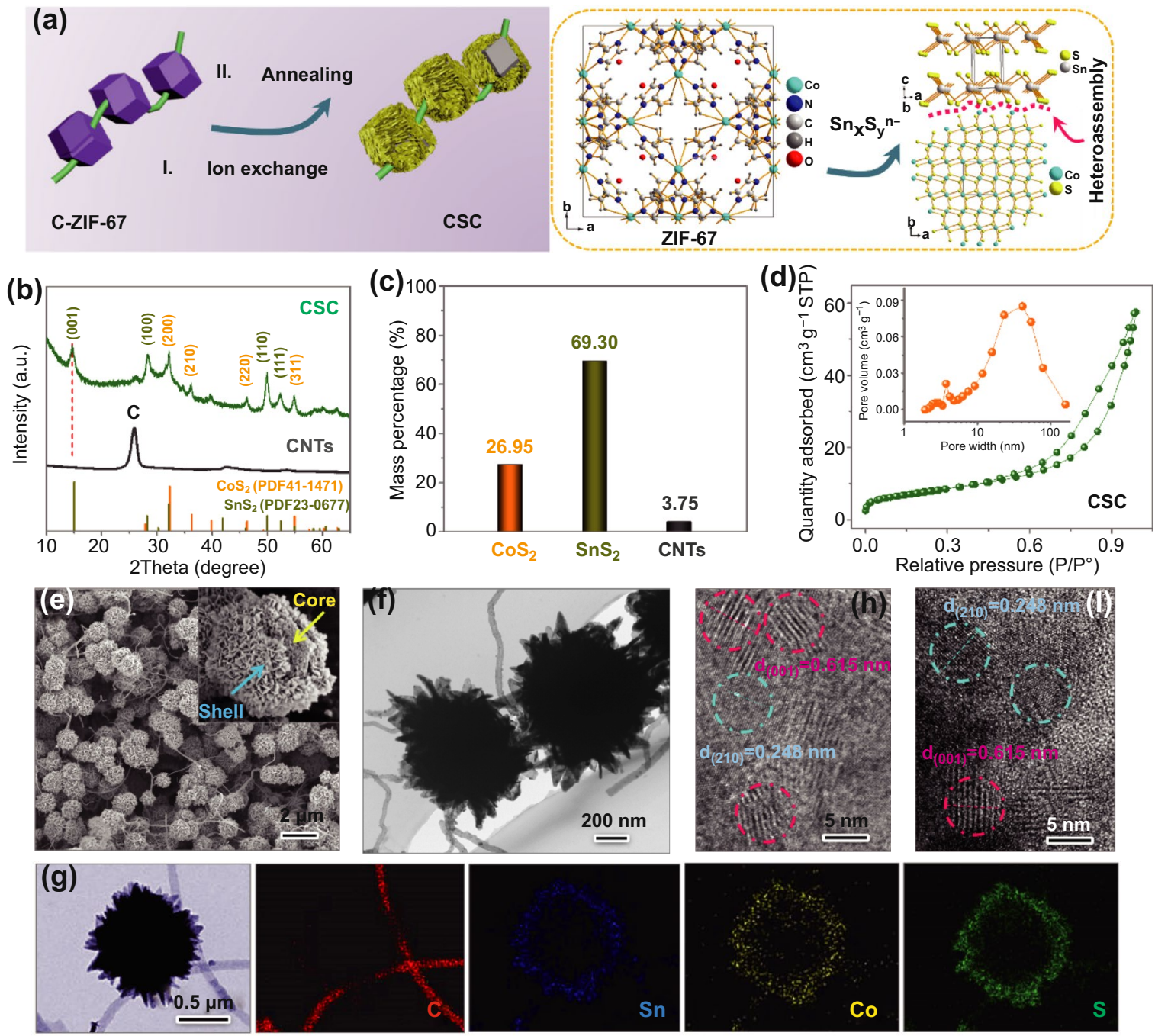

Fig. 1 a Schematic illustration of fabrication process of CSC, inset (right) showing the reaction between ZIF-67 and $\mathrm{Sn}_{x} \mathrm{~S}_{y}{ }^{\mathrm{n}-}$. $\mathbf{b}$ XRD patterns of CNTs and CSC. $\mathbf{c}$ Mass content of $\mathrm{CoS}_{2}, \mathrm{SnS}_{2}$, and CNTs in the CSC. $\mathbf{d} \mathrm{N}_{2}$ adsorption isotherm of CSC and corresponding pore width distribution. e FE-SEM images of CSC (inset displaying the core/shell structure of CSC). $\mathbf{f}$ TEM image of CSC and $\mathbf{g}$ TEM-EDS element mapping of CSC including C, Co, Sn, and S. HR-TEM images of $\mathbf{h}$ shell and $\mathbf{i}$ core in CSC showing co-assembly of nano-CoS $\mathrm{S}_{2}$ and $-\mathrm{SnS}_{2}$ 
the expanded interlayer spacing. Also, the relatively low annealing temperature $\left(450{ }^{\circ} \mathrm{C}\right)$ is beneficial to retain the expanded interlayer spacing of $\mathrm{SnS}_{2}$. The content of carbon nanotubes in CSC is obtained by thermogravimetric analysis (TGA), which is ca. $3.75 \mathrm{wt} \%$ (Fig. S3). By inductively coupled plasma-mass spectrometry (ICP-MS), the elemental content of CSC is analyzed, revealing that the mole ratio of $\mathrm{Co} / \mathrm{Sn} / \mathrm{S}$ is $c a .1 .00 / 1.73 / 5.46$ (Table $\mathrm{S} 1$ ). The corresponding mass content of $\mathrm{CoS}_{2}$ and $\mathrm{SnS}_{2}$ in the CSC is 26.95 and $69.30 \mathrm{wt} \%$, respectively (Fig. 1c). The type-IV $\mathrm{N}_{2}$ adsorption isotherms of CSC present an evident hysteresis loop, indicating the presence of mesopores (Fig. 1d). The corresponding pore width (inset) mainly centers in the range of 20-45 $\mathrm{nm}$. The theoretical capacity of CSC anode $\left(\mathrm{C}_{T \text {-CSC }}\right)$ can be evaluated roughly according to the equation: $\mathrm{C}_{T-\mathrm{CSC}}=x \mathrm{C}_{T-\mathrm{CoS} 2}+y \mathrm{C}_{T-\mathrm{SnS} 2}$, where $x$ and $y$ is the percentage content of $\mathrm{CoS}_{2}$ and $\mathrm{SnS}_{2}$ in the CSC. The $\mathrm{C}_{T \text {-CoS2 }}$ and $\mathrm{C}_{T \text {-SnS2 }}$ are the theoretical capacity of $\mathrm{CoS}_{2}$ and $\mathrm{SnS}_{2}$, which is 872 and $1136 \mathrm{mAh} \mathrm{g}^{-1}$, respectively. Thus, $\mathrm{C}_{T-\mathrm{CSC}}=0.2695 \times 872+0.695 \times 1136=1024.5 \mathrm{mAh} \mathrm{g}^{-1}$.

Figure 1e exhibits field emission scanning electron microscopy (FE-SEM) images of CSC, which consists of carbon nanotubes-stringed core/shell architecture (inset). Such core/shell structures are greatly influenced by precursors, solvents, reaction temperatures, and concentrations (Figs. S4-S6). The content of $\mathrm{SnS}_{2}$ in the CSC can be tuned to some extent by varying the concentration of thiostannate solution (Fig. S6). Transmission electron microscope (TEM) image shows the typical radial morphology of the CSC (Fig. 1f). Energy-dispersive spectrometer (EDS) elemental mapping yields a distribution of the elements $\mathrm{C}, \mathrm{Sn}, \mathrm{Co}$, and $\mathrm{S}$ in the CSC, which correspond well with the TEM image (Fig. 1g). The details of shell and core were further characterized by TEM. The shell is actually composed of nanosheets (Fig. S7a). As displayed in Fig. 1h, high-resolution transmission electron microscope (HR-TEM) image clearly exhibits interplanar spacings of 0.248 and $0.615 \mathrm{~nm}$ for $\mathrm{CoS}_{2}\left(\begin{array}{lll}2 & 1 & 0\end{array}\right)$ and $\mathrm{SnS}_{2}(0$ 0 1) lattice planes, verifying such nanosheets assembled by nano-dispersed $\mathrm{SnS}_{2}$ (red) and $\mathrm{CoS}_{2}$ (blue-green). The TEM-EDS line-scan profiles show matched peaks with Co, $\mathrm{Sn}, \mathrm{S}$ elements, further suggesting the superstructure of shell co-assembled by $\mathrm{SnS}_{2}$ and $\mathrm{CoS}_{2}$ phases (Fig. S7b). Corresponding to SEM image of CSC (inset), the core of CSC shows an abundant microstructure, in which the pore (green) can be observed (Fig. S8a). As shown in Fig. 1i,
HR-TEM image of the core also exposes the lattice planes of $\mathrm{SnS}_{2}\left(\begin{array}{lll}0 & 0 & 1\end{array}\right)$ and $\mathrm{CoS}_{2}\left(\begin{array}{lll}2 & 1 & 0\end{array}\right)$, which accord with the corresponding selected area electron diffraction (SAED) pattern (Fig. S8b). Such results verify that the core of CSC is also assembled by nano-dispersed $\mathrm{SnS}_{2}$ and $\mathrm{CoS}_{2}$ phases. The CSC was further analyzed by X-ray photoelectron spectroscopy (XPS). As shown in Fig. S9, compared with commercial $\mathrm{CoS}_{2}$ sample, the high-resolution of XPS of Co $2 p$ of CSC shows a ca. $0.45 \mathrm{eV}$ shift toward higher binding energy. Moreover, the high-resolution of XPS of Sn 3d of CSC also appears a $0.61 \mathrm{eV}$ shift toward higher binding energy. Such results imply the presence of chemical effect between $\mathrm{CoS}_{2}$ and $\mathrm{SnS}_{2}$ in CSC anodes [45, 46].

\subsection{Half-Cell Properties}

The electrochemical properties of anode materials are firstly evaluated by testing half-cells with $\mathrm{Na}$ foil as counter electrode and ether-based electrolytes with fluorine-containing sodium salt. For comparison, commercial $\mathrm{SnS}_{2}$ and $\mathrm{CoS}_{2}$ powders with well-matched XRD patterns to standard phases are also tested (Fig. S10). Compared with the CSC, the $\mathrm{N}_{2}$ isotherms of commercial $\mathrm{SnS}_{2}$ and $\mathrm{CoS}_{2}$ samples typically exhibit no evident hysteresis loop, whereby the corresponding pore diameter distributions display nonporous properties (Fig. S11). After initial three scans at $0.1 \mathrm{mV} \mathrm{s}^{-1}$, mono-component metal sulfides $\left(\mathrm{CoS}_{2}\right.$ and $\left.\mathrm{SnS}_{2}\right)$ and anodes composed of both compounds show gradually stabilized CV curves (Fig. S12). The initial CV curve of the CSC anode shows three oxidation peaks, which are associated with $\mathrm{SnS}_{2}$ phase at $0.70-1.55 \mathrm{~V}$ and $\mathrm{CoS}_{2}$ phase at $1.70-2.10 \mathrm{~V}$, respectively. The reduction peak at $1.60-1.80 \mathrm{~V}$ is correlated with the $\mathrm{CoS}_{2}$ phase, while the peaks at $0.50-1.10 \mathrm{~V}$ are linked to $\mathrm{SnS}_{2}$ and formation of solid electrolyte interphase (Fig. $\mathrm{S} 13 \mathrm{a}$ ). In subsequent scans, the reduction peak related to $\mathrm{CoS}_{2}$ gradually disappears, which could result from electrochemical activation of nano-dispersed $\mathrm{SnS}_{2}$ and $\mathrm{CoS}_{2}$ phases $[16,22]$. As shown in Fig. 2a, the activated CSC delivers a main oxidized peak potential range $(0.75-1.65 \mathrm{~V})$, which is close to that of $\mathrm{SnS}_{2}(0.80-1.45 \mathrm{~V})$ but remarkably lower than that of $\mathrm{CoS}_{2}(1.30-2.18 \mathrm{~V})$ and $\mathrm{SnS}_{2} / \mathrm{CoS}_{2}$ mixture (1.25-2.15 V). Correspondingly, CSC anode displays an average charge voltage of $c a .1 .30 \mathrm{~V}$, which is close to that of $\mathrm{SnS}_{2}$ but lower than that of $\mathrm{CoS}_{2}$ (ca. $1.92 \mathrm{~V}$ ) (Fig. 2b). Compared with commercial $\mathrm{SnS}_{2} / \mathrm{CoS}_{2}$ mixture with average 
charge voltage of $c a .1 .81 \mathrm{~V}, \mathrm{CSC}$ anode also shows evident low-plateau merit (Fig. 2c). This verifies that the construction of a superstructure assembled from nano-dispersed $\mathrm{SnS}_{2}$ and $\mathrm{CoS}_{2}$ phases is crucial for lowering the intrinsically high plateau of the $\mathrm{CoS}_{2}$ phase. Specifically, as shown in Fig. 2d, the introduction of nano-dispersed $\mathrm{SnS}_{2}$ phase into CSC effectively lowers the intrinsic average charge voltage of $\mathrm{CoS}_{2}$ up to $c a$. $0.62 \mathrm{~V}$. This in turn will translate to a higher plateau voltage for full-cells, thereby improving their energy density.
Compared with other metal chalcogenide anodes, CSC exhibits obvious high-capacity and low-plateau advantages (Fig. 2e). Moreover, compared with commercial $\mathrm{SnS}_{2}$ and $\mathrm{CoS}_{2}$, and mixtures of the two, CSC shows a remarkably improved rate capability, ranging from 0.5 to $20 \mathrm{~A} \mathrm{~g}^{-1}$ with a high capacity of $327.6 \mathrm{mAh} \mathrm{g}^{-1}$ anode at $20 \mathrm{~A} \mathrm{~g}^{-1}$ (Fig. 2f). The corresponding discharge/charge curves are exhibited in Fig. S14. When tested with ester-based electrolyte, CSC shows similar CV curves to that in ether-based electrolyte, but the reversible capacity, to the same cutoff
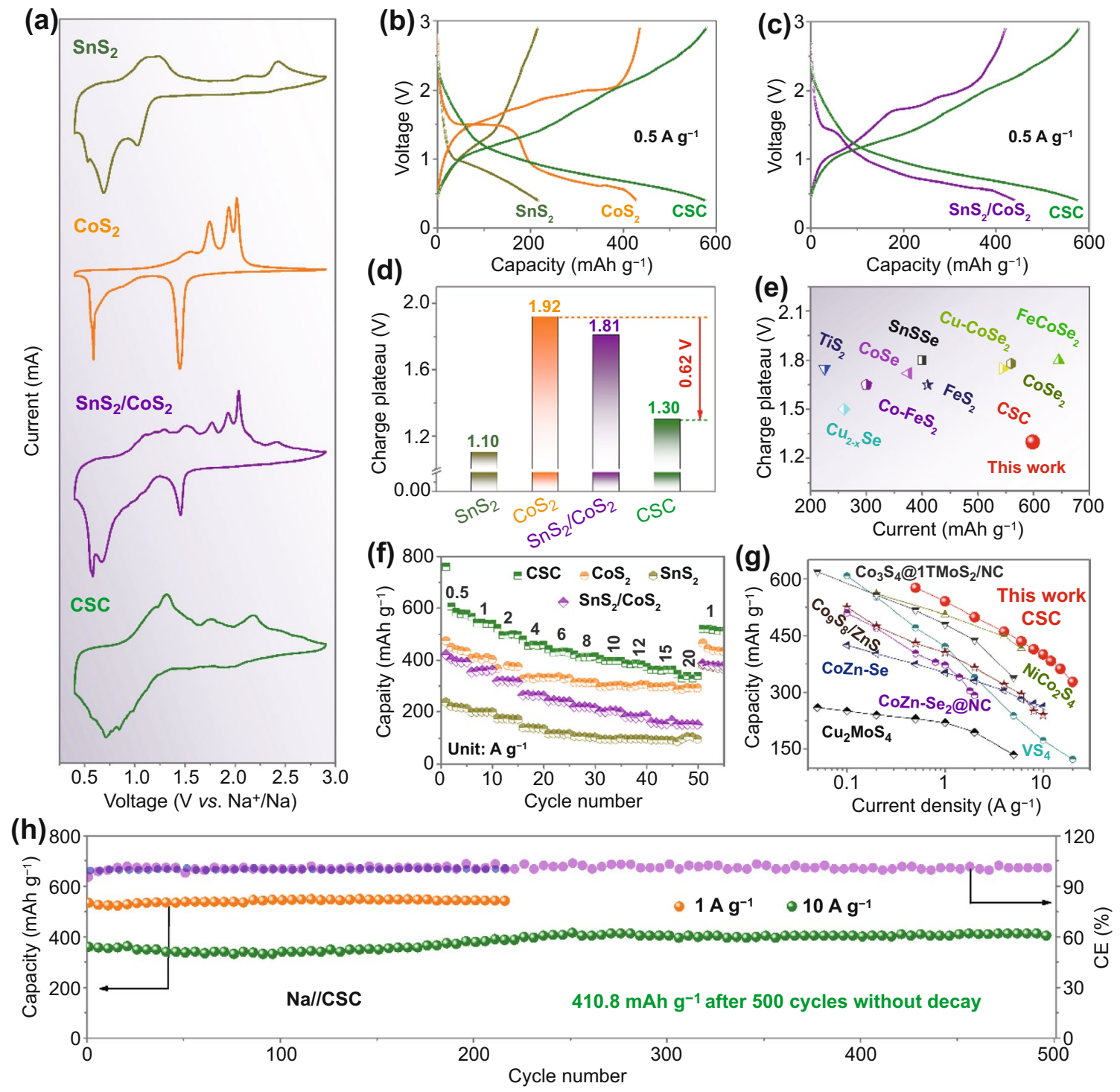

Fig. 2 a CV curves and b, c corresponding discharge-charge curves of CSC, commercial $\mathrm{SnS}_{2}$ and $\mathrm{CoS}_{2}$, and $\mathrm{SnS}_{2} / \mathrm{CoS}_{2}$ mixture. d Histogram showing the average charge plateau voltages of various anodes in half-cells. e Capacity/charge plateau comparison of different anodes. $\mathbf{f}$ Rate capability of CSC, commercial $\mathrm{SnS}_{2}$ and $\mathrm{CoS}_{2}$ in half-cells. g Rate capability comparison of different anodes. h Long-life cyclability of CSC anode at 1 and $10 \mathrm{~A} \mathrm{~g}^{-1}$ (CE Coulombic efficiency) 
voltage, shrinks markedly (Fig. S15). In addition, compared with in ether-based electrolyte, the rate capability of CSC is greatly deteriorated (Fig. S16), along with an increased resistance of charge transfer (Fig. S17). Such phenomena suggest the key role of ether-based electrolyte in stabilizing metal sulfide anodes and realizing fast charge transfer, which could be associated with good compatibility between metal sulfide and ether solvent [1, 15]. Evidently, the CSC anode effectively circumvents the intrinsic high voltage of $\mathrm{CoS}_{2}$ and low-rate drawback of $\mathrm{SnS}_{2}$ in etherbased electrolyte. Compared with other anode materials in half-cells, CSC also shows a remarkable high-rate capability (Fig. 2g, Table S2)_ENREF_12_ENREF_13_ENREF_14_ ENREF_15_ENREF_16_ENREF_17_ENREF_18 [47-54]. The CSC can be cycled at high current densities ( 1 and $10 \mathrm{~A}$ $\mathrm{g}^{-1}$ ) with excellent long-life cyclability, specifically, 410.8 $\mathrm{mAh} \mathrm{g}^{-1}$ anode at $10 \mathrm{~A} \mathrm{~g}^{-1}$ over 500 cycles without decay (Fig. 2h).

\subsection{Electrochemical Kinetics}

The electrochemical kinetics of the CSC anode in half-cells is studied in detail by reference to the results of electrochemical impedance spectroscopy (EIS). Compared with electrodes made from commercial samples of $\mathrm{SnS}_{2}$ and $\mathrm{CoS}_{2}$, the Nyquist curve for a typical CSC anode shows a semi-circle with smaller diameter, implying a faster charge transfer (Fig. 3a). Based on the derived equivalent circuit, the resistances of charge transfer for CSC, commercial $\mathrm{SnS}_{2}$ and $\mathrm{CoS}_{2}$ anodes are 9.5, 32.7, and $13.4 \Omega$, respectively (Fig. 3b). To compare $\mathrm{Na}^{+}$diffusion coefficient $\left(D_{\mathrm{Na}^{+}}\right)$in $\mathrm{CSC}$ and $\mathrm{SnS}_{2} / \mathrm{CoS}_{2}$ mixture, galvanostatic intermittent titration technique (GITT) was conducted at $0.05 \mathrm{~A} \mathrm{~g}^{-1}$ for $0.5 \mathrm{~h}$, followed by relaxation for $2 \mathrm{~h}$. The typical GITT discharge profiles of CSC and $\mathrm{SnS}_{2} / \mathrm{CoS}_{2}$ mixture are shown in Fig. 3c. As illustrated in Fig. $3 \mathrm{~d}, D_{\mathrm{Na}^{+}}$can be calculated following equation $D_{\mathrm{Na}^{+}}=\frac{4 L^{2}}{\pi \tau}\left(\frac{\Delta E_{S}}{\Delta E_{t}}\right)^{2}$, where $L$ is $\mathrm{Na}^{+}$diffusion length $(\mathrm{cm}), \tau$ is the current impulse time (s), $t$ is relaxation time (s), $\Delta E_{S}$ is steady-state potential change (V), $\Delta E_{t}$ is the instantaneous potential change $(\mathrm{V})$ used to deduce IR drop [55, 56]. Corresponding to the GITT profiles, the calculated average $D_{\mathrm{Na}^{+}}$is $c a .0 .5 \times 10^{-9} \mathrm{~cm}^{2} \mathrm{~s}^{-1}$, which is around twice that in half-cell with $\mathrm{SnS}_{2} / \mathrm{CoS}_{2}$ mixture (Fig. 3e). Evidently, compared with simply mixed $\mathrm{SnS}_{2} / \mathrm{CoS}_{2}$ anode, the CSC assembly of nano-dispersed $\mathrm{SnS}_{2}$ and $\mathrm{CoS}_{2}$ particles shows remarkable superiority in terms of charge transfer kinetics and ionic diffusion.

Next, the pseudocapacitive contribution to charge storage in the $\mathrm{Na} / / \mathrm{CSC}$ half-cell was evaluated, on the basis that this component gives rise to faster charge transfer kinetics. $\mathrm{CV}$ curves at different rates are shown in Fig. 3f, and the correlation of peak currents $(i)$ and scan rates $(v)$ was assessed against the relationship $i=a v^{b}$, where $a$ and $b$ are adjustable constants [57]. As shown in Fig. 3g, the resultant $b$-values are $0.98,0.81$, and 0.93 , respectively, which implies the presence of a substantial pseudocapacitive contribution. The latter can be quantified through the equation $i=k_{1} v+k_{2} v^{1 / 2}$, where $k_{1} v$ and $k_{2} v^{1 / 2}$ represent pseudocapacitive and iondiffusion controlled contribution, respectively [57-59]. As shown in Fig. 3h, CSC anodes exhibit dominant pseudocapacitive contributions at scan rates of $0.1,0.2,0.4,0.8$, and $1.5 \mathrm{mV} \mathrm{s}^{-1}$, specifically, $64.0 \%, 67.0 \%, 71.6 \%, 78.3 \%$, and $86.3 \%$, respectively. Figure $3 i$ displays the $\mathrm{CV}$ curves of $\mathrm{Na} / /$ $\mathrm{CSC}$ at $1.5 \mathrm{mV} \mathrm{s}^{-1}$, in which the shaded region represents the pseudocapacitive contribution. This, together with the small charge transfer resistance and high $D_{\mathrm{Na}^{+}}$, explains the excellent rate capability of the CSC anode.

\subsection{Electrochemical Mechanism}

To investigate the mechanism that underpins the superior electrochemical behavior of CSC anodes, samples were at various states-of-(dis)charge characterized by ex situ XRD. The copper current collector in a $\mathrm{Na} / / \mathrm{Cu}$ half-cell discharged to $0.4 \mathrm{~V}$ shows only the intrinsic diffraction peaks for metallic copper, verifying no evident electrochemical reaction between $\mathrm{Na}$ and $\mathrm{Cu}$ collector in etherbased electrolyte (Fig. S18). Compared with original samples (CSC, commercial $\mathrm{SnS}_{2}$ and $\mathrm{CoS}_{2}$ ), the samples after electrochemical activation exhibit dramatically different XRD patterns, indicating the occurrence of phase transition (Fig. S19). For $\mathrm{CoS}_{2}$, the relevant electrochemical reactions are as follows: $\mathrm{CoS}_{2}+x \mathrm{Na}^{+}+x \mathrm{e}^{-} \rightarrow \mathrm{Na}_{x} \mathrm{CoS}_{2}$, $\mathrm{Na}_{x} \mathrm{CoS}_{2}+(4-x) \mathrm{Na}^{+}+(4-x) \mathrm{e}^{-} \leftrightarrow 2 \mathrm{Na}_{2} \mathrm{~S}+\mathrm{Co}$ [60]. For $\mathrm{SnS}_{2}$, the corresponding electrochemical reactions are as follows: $x \mathrm{Na}^{+}+\mathrm{SnS}_{2}+x \mathrm{e}^{-} \rightarrow \mathrm{Na}_{x} \mathrm{SnS}_{2}, \mathrm{Na}_{x} \mathrm{SnS}_{2}+(4-x)$ $\mathrm{Na}^{+}+(4-x) \mathrm{e}^{-} \leftrightarrow 2 \mathrm{Na}_{2} \mathrm{~S}+\mathrm{Sn}, \mathrm{Sn}+\mathrm{yNa}^{+}+\mathrm{ye}^{-} \leftrightarrow \mathrm{Na}_{\mathrm{y}} \mathrm{Sn}$ [40, 61]. Compared with single phases, the CSC anode shows similar featured diffraction peaks to pure $\mathrm{SnS}_{2}$, 

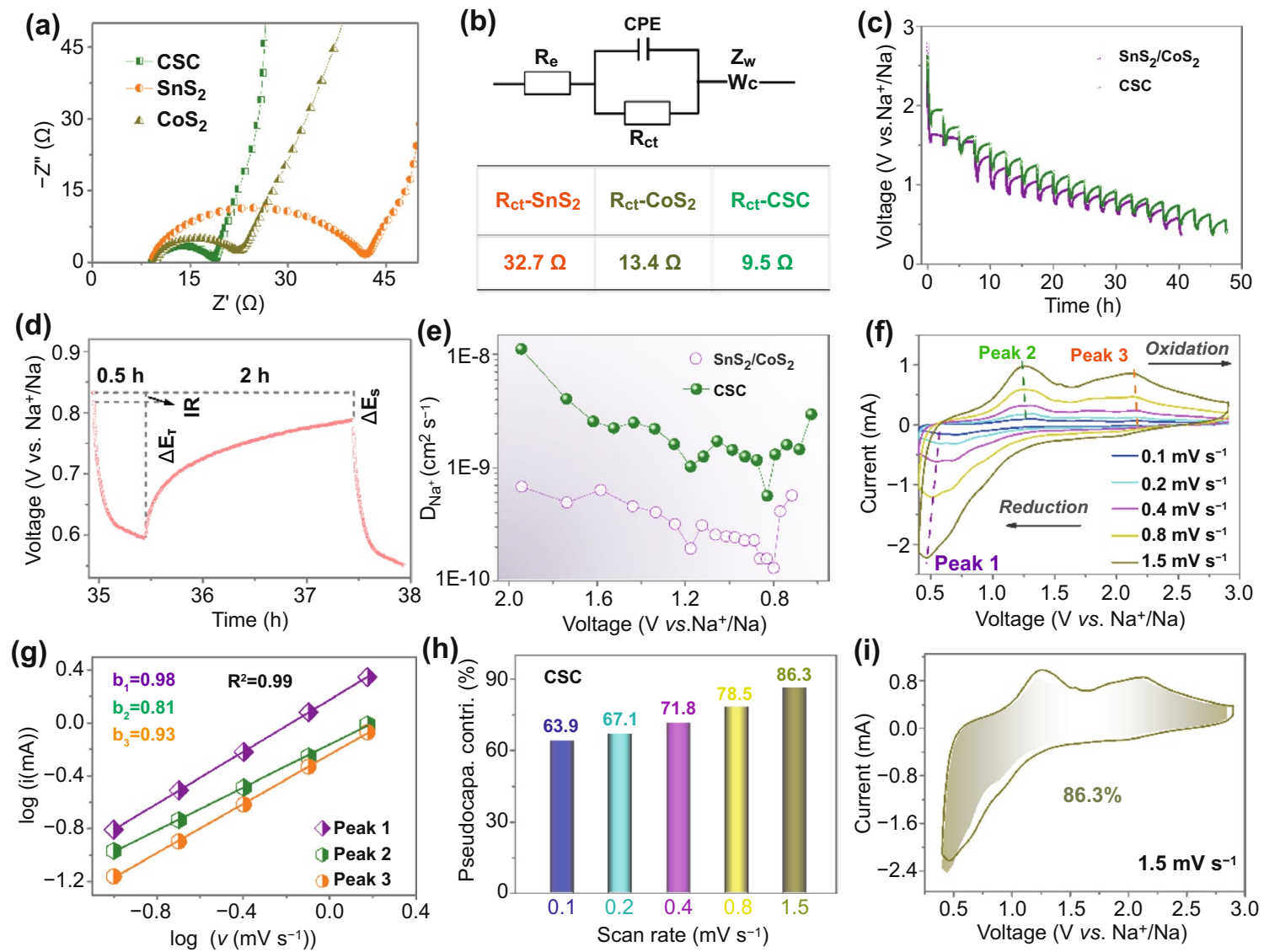

Fig. 3 a Nyquist plots of different anodes in half-cells and $\mathbf{b}$ corresponding equivalent circuit and charge transfer resistance $\left(R_{\mathrm{ct}}\right)$. $\mathbf{c}$ GITT profiles of Na//CSC half-cell discharged and $\mathbf{d}$ typical profile in a single GITT test. e $\mathrm{Na}^{+}$diffusion coefficient distribution corresponding to a typical discharge curve of $\mathrm{Na} / \mathrm{CSC}$ half-cell (inset). $\mathbf{f ~ C V}$ curves of Na//CSC half-cell at different scan rates. $\mathbf{g} b$-values obtained by fitting peak current-scan rate correlation based on CV curves of Na//CSC half-cell. $\mathbf{h}$ Pseudocapacitive contribution (pseudocapa. contri.) of Na//CSC at different scan rates. i CV profiles of $\mathrm{Na} / / \mathrm{CSC}$ at $1.5 \mathrm{mV} \mathrm{s}^{-1}$ and corresponding pseudocapacitive contribution (shaded region)

while the peaks from the $\mathrm{CoS}_{2}$ diffraction pattern are difficult to discern. This could be associated with differences in crystallinity between products derived from $\mathrm{SnS}_{2}$ and $\mathrm{CoS}_{2}$. For investigating the mechanism of activated CSC, original CSC anodes were activated for at least 3 cycles to obtain phase-transformed materials. Corresponding to the discharge-charge-time curves in Fig. 4a, the activated CSC anodes at various states-of-charge show repeatable XRD patterns, implying good reversibility during the discharge/ charge processes (Fig. 4b). The peak intensity of XRD pattern of anode (such as C-0.97 V, blue) is lower than that of initially charged anode (such as C-0.97 V, pink), which could be associated with the decreased diameter and gradually aggravated amorphization of metal sulfide phases. Similar phenomena have been reported in other metal chalcogenide anodes such as $\mathrm{CoSe}_{2}$ and $\mathrm{CoS}_{2}[13,60]$. At different (dis)charge states, the corresponding XRD of anodes shows different patterns, which should be correlated to the successive formation of different products.

As shown in Fig. 4c, HR-TEM image of CSC discharged to $0.4 \mathrm{~V}$ displays interplanar spacings of 0.569 and $0.316 \mathrm{~nm}$, corresponding to lattice plane $\left(\begin{array}{lll}0 & 0 & 4\end{array}\right)$ of $\mathrm{Na}_{29.58} \mathrm{Sn}_{8}$ and $\left(\begin{array}{lll}1 & 0 & 1\end{array}\right)$ of Co. Selected area electron diffraction (SAED) patterns reveal the lattice plane $\left(\begin{array}{lll}2 & 1 & 1\end{array}\right)$ of Co, ( $\left.\begin{array}{lll}5 & 1 & 3\end{array}\right)$ and ( $\left.\begin{array}{lll}1 & 3 & 1\end{array}\right)$ of $\mathrm{Na}_{29.58} \mathrm{Sn}_{8}$ in the discharged product (Fig. $4 \mathrm{~d}$ ). When charged back to $2.9 \mathrm{~V}$, the crystalline domains in the resulting product are remarkably smaller than those in the discharged state. As shown in Fig. 4e, HR-TEM image of CSC charged to $2.9 \mathrm{~V}$ displays interplanar spacings of 0.184 and $0.295 \mathrm{~nm}$, which are 

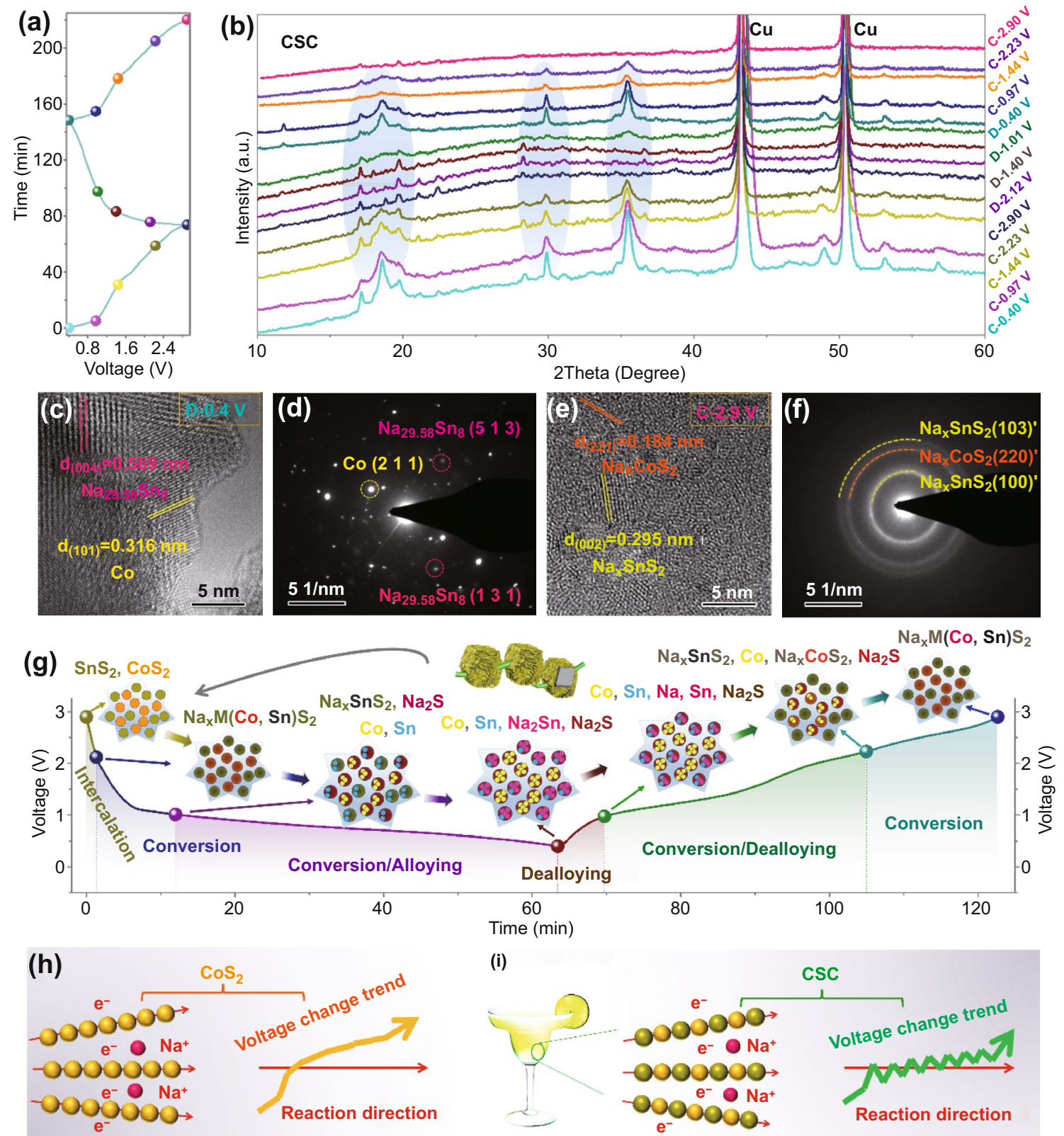

(i)

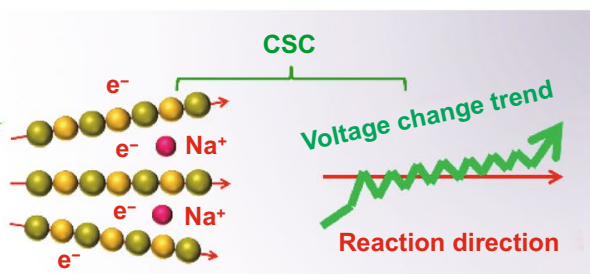

Fig. 4 a Discharge-charge-time curve and $\mathbf{b}$ ex situ XRD patterns of CSC anode at different potentials. $\mathbf{c}$ HR-TEM image and d SAED pattern of CSC discharged to $0.4 \mathrm{~V}$. e HR-TEM image and f SAED pattern of CSC charged to $2.9 \mathrm{~V}$. $\mathbf{g}$ Schematic illustration of discharge/charge mechanisms of CSC anode. $\mathbf{h}$ Schematic illustration of reaction route and charge voltage change trend of $\mathrm{CoS}_{2}$ anode. $\mathbf{i}$ Schematic illustration of reaction route and charge voltage change trend of CSC anode, showing cocktail mediation effect among nano-dispersed metal sulfide phases in CSC

assigned to lattice plane of (2 2 1)' of $\mathrm{Na}_{x} \mathrm{CoS}_{2}$ and (0 0 2)' of $\mathrm{Na}_{x} \mathrm{SnS}_{2}$ (with $\mathrm{CoS}_{2}$ and $\mathrm{SnS}_{2}$ standard phases as reference), respectively. The SAED pattern exhibits typical polycrystalline features, in which lattice plane $(2$ $20)$ of $\mathrm{Na}_{x} \mathrm{CoS}_{2},\left(\begin{array}{lll}1 & 0 & 3\end{array}\right)$ and $\left(\begin{array}{lll}1 & 0 & 0\end{array}\right)$ of $\mathrm{Na}_{x} \mathrm{SnS}_{2}$ can be identified (Fig. 4f). Based on the characterization above, the progress of electrochemical reduction, followed by oxidation, for the CSC electrode is illustrated in Fig. 4g. Typically, $\mathrm{SnS}_{2}$ and $\mathrm{CoS}_{2}$ phases in CSC experience an initial phase transition to $\mathrm{Na}^{+}$-intercalated intermediates $\left(\mathrm{Na}_{x} \mathrm{MS}_{2}, \mathrm{M}=\mathrm{Sn}, \mathrm{Co}\right)$, which act as active materials for subsequent discharge/charge cycles. Based on the analysis 
above, the exotic property mediation beyond rule-of-mixtures $[35,36]$ (cocktail mediation effect) among nanodispersed $\mathrm{SnS}_{2}$ and $\mathrm{CoS}_{2}$ phases in CSC is schematically illustrated in Fig. 4h-i. Specifically, along the different ionic diffusion directions, the nano-dispersed $\mathrm{SnS}_{2}$ and $\mathrm{CoS}_{2}$ phases in CSC will alternatively react with $\mathrm{Na}^{+}$carriers, as schematically illustrated in Fig. 4i. The nanodispersion of $\mathrm{SnS}_{2}$ and $\mathrm{CoS}_{2}$ phases effectively shortens the ion diffusion path, which can kinetically boost electrochemical processes of both metal sulfide anodes. Due to intrinsic thermodynamics difference, the electrochemical competition is present between $\mathrm{SnS}_{2}$ and $\mathrm{CoS}_{2}$ phases. Also, it does not exclude one of the two phases could show local kinetic merit owing to the diameter difference between them. Thus, in the CSC anode, the alternative electrochemical reaction processes could coexist between the two phases. It enables complementary charge voltage plateau of different metal sulfide phases, resulting in lowered charge plateau of CSC anode.

\subsection{Full-Cell Properties}

To verify the practicability of the CSC anode, a highvoltage cathode material $\mathrm{Na}_{1.5} \mathrm{VPO}_{4.8} \mathrm{~F}_{0.7}$ was employed to assemble CSC//Na ${ }_{1.5} \mathrm{VPO}_{4.8} \mathrm{~F}_{0.7}$ full-cells. Synthesis of $\mathrm{Na}_{1.5} \mathrm{VPO}_{4.8} \mathrm{~F}_{0.7}$ followed a modified literature method (Supporting Information), and yielded a micro-particle morphology with a well-matched XRD pattern with the standard phase (Fig. S20) [33]. Corresponding to CV curves, $\mathrm{Na}_{1.5} \mathrm{VPO}_{4.8} \mathrm{~F}_{0.7}$ cathode shows ca. $3.9 \mathrm{~V}$ discharge plateau with low electrochemical polarization, which is suitable for demonstrating the practicability of different anodes (Fig. S21a, b). The $\mathrm{Na}_{1.5} \mathrm{VPO}_{4.8} \mathrm{~F}_{0.7}$ cathode delivers a good rate capability from 0.05 to $0.5 \mathrm{~A} \mathrm{~g}^{-1}$, showing a high reversible capacity of $124.1 \mathrm{mAh} \mathrm{g}^{-1}$ electrode at $0.05 \mathrm{~A} / \mathrm{g}$ (Fig. S21c, d). Over 350 cycles at $0.1 \mathrm{~A} \mathrm{~g}^{-1}$, the $\mathrm{Na}_{1.5} \mathrm{VPO}_{4.8} \mathrm{~F}_{0.7}$ cathode shows a capacity of $106.4 \mathrm{mAh}$ $\mathrm{g}^{-1}$ electrode, corresponding to a low capacity decay of $0.02 \%$ per cycle (Fig. S22). Figure 5a shows the typical CV curves
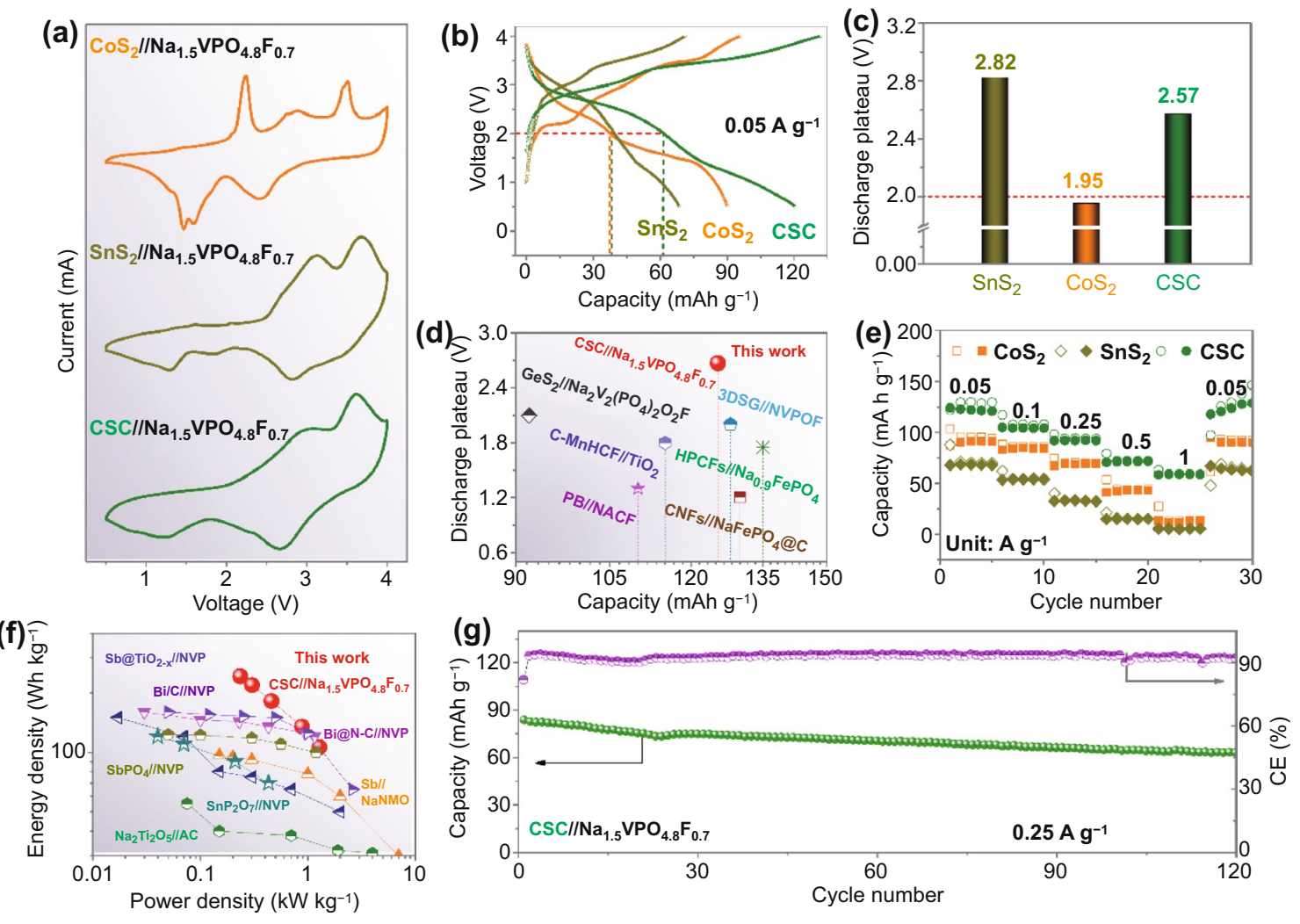

Fig. 5 a CV curves of $\mathrm{CoS}_{2} / / \mathrm{Na}_{1.5} \mathrm{VPO}_{4.8} \mathrm{~F}_{0.7}, \mathrm{SnS}_{2} / / \mathrm{Na}_{1.5} \mathrm{VPO}_{4.8} \mathrm{~F}_{0.7}$, and $\mathrm{CSC} / / \mathrm{Na}_{1.5} \mathrm{VPO}_{4.8} \mathrm{~F}_{0.7}$ full-cells at $0.5 \mathrm{mV} \mathrm{s}^{-1}$. b Corresponding discharge/charge curves and $\mathbf{c}$ discharge plateaus of full-cells at $0.05 \mathrm{~A} \mathrm{~g}^{-1}$. d Discharge plateau/capacity comparison of different full-cells. e Rate capability of $\mathrm{CoS}_{2} / / \mathrm{Na}_{1.5} \mathrm{VPO}_{4.8} \mathrm{~F}_{0.7}, \mathrm{SnS}_{2} / / \mathrm{Na}_{1.5} \mathrm{VPO}_{4.8} \mathrm{~F}_{0.7}$, and $\mathrm{CSC} / / \mathrm{Na}_{1.5} \mathrm{VPO}_{4.8} \mathrm{~F}_{0.7}$ full-cells. f Ragone plots comparison of different fullcells. g Long-life cyclability of CSC//Na $1.5 \mathrm{VPO}_{4.8} \mathrm{~F}_{0.7}$ full-cells at $0.25 \mathrm{~A} \mathrm{~g}^{-1}$ 
of $\mathrm{CoS}_{2} / / \mathrm{Na}_{1.5} \mathrm{VPO}_{4.8} \mathrm{~F}_{0.7}, \mathrm{SnS}_{2} / / \mathrm{Na}_{1.5} \mathrm{VPO}_{4.8} \mathrm{~F}_{0.7}$, and CSC// $\mathrm{Na}_{1.5} \mathrm{VPO}_{4.8} \mathrm{~F}_{0.7}$ full-cells at $0.5 \mathrm{mV} \mathrm{s}^{-1}$. Evidently, the main redox peaks of $\mathrm{CoS}_{2} / / \mathrm{Na}_{1.5} \mathrm{VPO}_{4.8} \mathrm{~F}_{0.7}$ appear at $1.0-2.5 \mathrm{~V}$, implying that its average discharge voltage is in the range. In contrast, the ranges of main redox peaks of $\mathrm{SnS}_{2} / /$ $\mathrm{Na}_{1.5} \mathrm{VPO}_{4.8} \mathrm{~F}_{0.7}$ and $\mathrm{CSC} / / \mathrm{Na}_{1.5} \mathrm{VPO}_{4.8} \mathrm{~F}_{0.7}$ full-cells are in 2.0-4.0 V, which imply a higher average discharge voltage than that of the former. Figure $5 b$ shows that the discharge capacity available from the $\mathrm{CSC} / / \mathrm{Na}_{1.5} \mathrm{VPO}_{4.8} \mathrm{~F}_{0.7}$ cell, while the voltage is above $2 \mathrm{~V}$, is $c a .61 .7 \mathrm{mAh} \mathrm{g}^{-1}$ electrode, which is 1.62 times that of $\mathrm{CoS}_{2} / / \mathrm{Na}_{1.5} \mathrm{VPO}_{4.8} \mathrm{~F}_{0.7}$. As displayed in Fig. $5 \mathrm{c}, \mathrm{CSC} / / \mathrm{Na}_{1.5} \mathrm{VPO}_{4.8} \mathrm{~F}_{0.7}$ full-cells present an average discharge voltage of $2.57 \mathrm{~V}$, which is close to that of $\mathrm{SnS}_{2} / /$ $\mathrm{Na}_{1.5} \mathrm{VPO}_{4.8} \mathrm{~F}_{0.7}$ and $c a .0 .62 \mathrm{~V}$ higher than that with $\mathrm{CoS}_{2}$ anode. The CSC anode confers a significantly higher average voltage during discharge of full-cells when compared with $\mathrm{CoS}_{2}$ cells. Compared with other full-cells reported previously, $\mathrm{CSC} / / \mathrm{Na}_{1.5} \mathrm{VPO}_{4.8} \mathrm{~F}_{0.7}$ full-cells also show obvious merits in terms of discharge voltage and capacity (Fig. 5d). Moreover, $\mathrm{CSC} / / \mathrm{Na}_{1.5} \mathrm{VPO}_{4.8} \mathrm{~F}_{0.7}$ full-cells show a high-rate capability from 0.05 to $1 \mathrm{~A} \mathrm{~g}^{-1}$, delivering a high capacity of $120.3 \mathrm{mAh} \mathrm{g}^{-1}$ electrode at $0.05 \mathrm{~A} \mathrm{~g}^{-1}$ (Fig. 5e). The corresponding discharge/charge curves are shown in Fig. S23, where the voltage plateaus are well-retained. As exhibited in Fig. 5f, compared with other full-cells with different electrode materials, $\mathrm{CSC} / \mathrm{Na}_{1.5} \mathrm{VPO}_{4.8} \mathrm{~F}_{0.7}$ full-cell delivers comparable merits in terms of energy/power density. [62-67] Specifically, $106.1 \mathrm{Wh} \mathrm{kg}^{-1}$ electrode $/ 1278.3 \mathrm{~W} \mathrm{~kg}^{-1}$ electrode are achieved at $1 \mathrm{~A} \mathrm{~g}^{-1}$. When operated over 120 cycles at $0.25 \mathrm{~A} \mathrm{~g}^{-1}, \mathrm{CSC} / / \mathrm{Na}_{1.5} \mathrm{VPO}_{4.8} \mathrm{~F}_{0.7}$ full-cell shows a high capacity of $63.0 \mathrm{mAh} \mathrm{g}^{-1}$ electrode with a low decay of $0.20 \%$ per cycle (Fig. $5 \mathrm{~g}$ ). Such results suggest a good practicability of CSC in full-cells.

\section{Conclusions}

Despite with high-capacity and low-cost merits, the ubiquitous low-rate and high-plateau issues greatly lower the practicability of metal sulfide anodes in full-cells. Herein, enlightened by electrolyte/structure-dependent properties of metal sulfides, CSC anode assembled by nano-dispersed $\mathrm{SnS}_{2}$ and $\mathrm{CoS}_{2}$ phases is engineered as a case study in ether-based electrolyte, simultaneously realizing high-rate and low-plateau properties. The high nano-dispersity of metal sulfides endows CSC anode with evident cocktail mediation effect similar to high-entropy materials, effectively circumventing intrinsic drawbacks of different metal sulfides. The utilized ether-based electrolyte greatly enhances the reversibility of metal sulfides, sustaining a long-life effectivity of cocktail-like mediation. In half-cells, CSC delivers an ultrahigh-rate capability of $327.6 \mathrm{mAh} \mathrm{g}^{-1}$ anode at $20 \mathrm{~A} \mathrm{~g}^{-1}$ and remarkably lowered average charge voltage up to $c a .0 .62 \mathrm{~V}$, far outperforming $\mathrm{CoS}_{2}$ phase and $\mathrm{SnS}_{2} / \mathrm{CoS}_{2}$ mixture. The as-assembled $\mathrm{CSC} / / \mathrm{Na}_{1.5} \mathrm{VPO}_{4.8} \mathrm{~F}_{0.7}$ full-cell shows a good rate capability $\left(0.05-1.0 \mathrm{~A} \mathrm{~g}^{-1}, 120.3 \mathrm{mAh} \mathrm{g}^{-1}\right.$ electrode at $0.05 \mathrm{~A}$ $\mathrm{g}^{-1}$ ) and a high average discharge voltage up to $2.57 \mathrm{~V}$, comparable to full-cells with alloy-type anodes. Kinetics and mechanism studies further verify that the cocktail-like mediation effect largely boosts charge transfer and ionic diffusion in CSC, while alternative and complementary electrochemical processes between different nano-dispersed metal sulfides $\left(\mathrm{SnS}_{2}\right.$ and $\left.\mathrm{CoS}_{2}\right)$ and $\mathrm{Na}^{+}$carriers account for the lowered charge plateau of CSC. This work shows a unique electrolyte/structure-dependent cocktaillike mediation effect of metal sulfide anodes, which will boost the development of high-rate/-voltage sodium-ion full batteries.

Acknowledgements This work was supported by Guangdong Basic and Applied Basic Research Foundation, China (No. 2019A1515110980), research project from the National Natural Science Foundation of China (No. 21361162004), China Scholarship Council, and CSIRO. We acknowledge Dr Yesim Gozukara, Dr Malisja de Vries, and Dr Yunxia Yang from CSIRO (Clayton) for their help with material characterization training.

Open Access This article is licensed under a Creative Commons Attribution 4.0 International License, which permits use, sharing, adaptation, distribution and reproduction in any medium or format, as long as you give appropriate credit to the original author(s) and the source, provide a link to the Creative Commons licence, and indicate if changes were made. The images or other third party material in this article are included in the article's Creative Commons licence, unless indicated otherwise in a credit line to the material. If material is not included in the article's Creative Commons licence and your intended use is not permitted by statutory regulation or exceeds the permitted use, you will need to obtain permission directly from the copyright holder. To view a copy of this licence, visit http://creativecommons.org/licenses/by/4.0/.

Supplementary Information The online version contains supplementary material available at https://doi.org/10.1007/ s40820-021-00686-4. 


\section{References}

1. Z. Hu, Q. Liu, S.L. Chou, S.X. Dou, Advances and challenges in metal sulfides/selenides for next-generation rechargeable sodium-ion batteries. Adv. Mater. 29(48), 1700606 (2017). https://doi.org/10.1002/adma.201700606

2. Y. Fang, D. Luan, X.W. Lou, Recent advances on mixed metal sulfides for advanced sodium-ion batteries. Adv. Mater. 32(42), 2002976 (2020). https://doi.org/10.1002/ adma.202002976

3. Y. Tang, Z. Zhao, X. Hao, Y. Wang et al., Engineering hollow polyhedrons structured from carbon-coated $\mathrm{CoSe}_{2}$ nanospheres bridged by cnts with boosted sodium storage performance. J. Mater. Chem. A 5(26), 13591-13600 (2017). https://doi.org/10.1039/C7TA02665J

4. Y. Tang, Z. Zhao, X. Hao, Y. Wei et al., Cellular carbonwrapped $\mathrm{FeSe}_{2}$ nanocavities with ultrathin walls and multiple rooms for ion diffusion-confined ultrafast sodium storage. J. Mater. Chem. A 7(9), 4469-4479 (2019). https://doi. org/10.1039/C8TA10614B

5. Y. Xiao, S.H. Lee, Y.-K. Sun, The application of metal sulfides in sodium ion batteries. Adv. Energy Mater. 7(3), 1601329 (2017). https://doi.org/10.1002/aenm.201601329

6. J. Wang, L. Wang, C. Eng, J. Wang, Elucidating the irreversible mechanism and voltage hysteresis in conversion reaction for high-energy sodium-metal sulfide batteries. Adv. Energy Mater. 7(14), 1602706 (2017). https://doi.org/10. 1002/aenm.201602706

7. Q. Guo, Y. Ma, T. Chen, Q. Xia et al., Cobalt sulfide quantum dot embedded N/S-doped carbon nanosheets with superior reversibility and rate capability for sodium-ion batteries. ACS Nano 11(12), 12658-12667 (2017). https://doi.org/10. 1021/acsnano.7b07132

8. X.-W. Lou, Bullet-like $\mathrm{Cu}_{9} \mathrm{~S}_{5}$ hollow particles coated with nitrogen-doped carbon for sodium-ion batteries. Angew. Chem. Int. Ed. 131(23), 7826-7830 (2019). https://doi.org/ 10.1002/ange.201902988

9. Y. Tang, X. Li, H. Lv, D. Xie et al., Stabilized $\mathrm{Co}^{3+} / \mathrm{Co}^{4+}$ redox pair in in situ produced $\mathrm{CoSe}_{2-\mathrm{x}}$-derived cobalt oxides for alkaline $\mathrm{Zn}$ batteries with 10,000-cycle lifespan and 1.9-V voltage plateau. Adv. Energy Mater. 10(25), 2000892 (2020). https://doi.org/10.1002/aenm.202000892

10. A. Eftekhari, Low voltage anode materials for lithium-ion batteries. Energy Storage Mater. 7, 157-180 (2017). https:// doi.org/10.1016/j.ensm.2017.01.009

11. X. Li, Y. Tang, J. Zhu, H. Lv et al., Boosting the cycling stability of aqueous flexible $\mathrm{Zn}$ batteries via $\mathrm{F}$ doping in nickel-cobalt carbonate hydroxide cathode. Small 16(31), 2001935 (2020). https://doi.org/10.1002/smll.202001935

12. D. Chao, W. Zhou, F. Xie, C. Ye et al., Roadmap for advanced aqueous batteries: from design of materials to applications. Sci. Adv. 6(21), eaba4098 (2020). https://doi. org/10.1126/sciadv.aba4098

13. K. Zhang, M. Park, L. Zhou, G.-H. Lee et al., Urchin-like $\mathrm{CoSe}_{2}$ as a high-performance anode material for sodium-ion batteries. Adv. Funct. Mater. 26(37), 6728-6735 (2016). https://doi.org/10.1002/adfm.201602608

14. Y. Tang, Z. Zhao, Y. Wang, Y. Dong et al., Carbon-stabilized interlayer-expanded few-layer $\mathrm{MoSe}_{2}$ nanosheets for sodium ion batteries with enhanced rate capability and cycling performance. ACS Appl. Mater. Interfaces 8(47), 32324-32332 (2016). https://doi.org/10.1021/acsami.6b11230

15. S. Qi, L. Mi, K. Song, K. Yang et al., Understanding shuttling effect in sodium ion batteries for the solution of capacity fading: $\mathrm{FeS}_{2}$ as an example. J. Phys. Chem. C 123(5), 2775-2782 (2019). https://doi.org/10.1021/acs.jpcc.8b110 69

16. C. Dong, L. Guo, H. Li, B. Zhang et al., Rational fabrication of $\mathrm{CoS}_{2} / \mathrm{Co}_{4} \mathrm{~S}_{3} @ \mathrm{~N}$-doped carbon microspheres as excellent cycling performance anode for half/full sodium ion batteries. Energy Storage Mater. 25, 679-686 (2020). https://doi.org/10. 1016/j.ensm.2019.09.019

17. Z. Man, P. Li, D. Zhou, Y. Wang et al., Two birds with one stone: $\mathrm{FeS}_{2} @ \mathrm{C}$ yolk-shell composite for high-performance sodium-ion energy storage and electromagnetic wave absorption. Nano Lett. 20(5), 3769-3777 (2020). https://doi.org/10. 1021/acs.nanolett.0c00789

18. S. Li, W. He, B. Liu, J. Cui et al., One-step construction of three-dimensional nickel sulfide-embedded carbon matrix for sodium-ion batteries and hybrid capacitors. Energy Storage Mater. 25, 636-643 (2020). https://doi.org/10.1016/j.ensm. 2019.09.021

19. Y. Tang, Z. Zhao, Y. Wang, Y. Dong et al., Ultrasmall $\mathrm{MoS}_{2}$ nanosheets mosaiced into nitrogen-doped hierarchical porous carbon matrix for enhanced sodium storage performance. Electrochim. Acta 225, 369-377 (2017). https://doi.org/10. 1016/j.electacta.2016.12.176

20. Y. Li, Y.-S. Hu, M.-M. Titirici, L. Chen et al., Hard carbon microtubes made from renewable cotton as high-performance anode material for sodium-ion batteries. Adv. Energy Mater. 6(18), 1600659 (2016). https://doi.org/10.1002/aenm.20160 0659

21. H. Jin, H. Lu, W. Wu, S. Chen et al., Tailoring conductive networks within hollow carbon nanospheres to host phosphorus for advanced sodium ion batteries. Nano Energy 70, 104569 (2020). https://doi.org/10.1016/j.nanoen.2020.104569

22. K. Zhang, M. Park, L. Zhou, G.-H. Lee et al., Cobalt-doped $\mathrm{FeS}_{2}$ nanospheres with complete solid solubility as a highperformance anode material for sodium-ion batteries. Angew. Chem. Int. Ed. 55(41), 12822-12826 (2016). https://doi.org/ 10.1002/anie.201607469

23. Y. Liu, Y. Yang, X. Wang, Y. Dong et al., Flexible paper-like free-standing electrodes by anchoring ultrafine $\mathrm{SnS}_{2}$ nanocrystals on graphene nanoribbons for high-performance sodium ion batteries. ACS Appl. Mater. Interfaces 9(18), 1548415491 (2017). https://doi.org/10.1021/acsami.7b02394

24. Z. Liu, A. Daali, G.-L. Xu, M. Zhuang et al., Highly reversible sodiation/desodiation from a carbon-sandwiched $\mathrm{SnS}_{2}$ nanosheet anode for sodium ion batteries. Nano Lett. 20(5), 3844-3851 (2020). https://doi.org/10.1021/acs.nanolett.0c009 64 
25. X. Ou, L. Cao, X. Liang, F. Zheng et al., Fabrication of $\mathrm{SnS}_{2} /$ $\mathrm{Mn}_{2} \mathrm{SnS}_{4} /$ carbon heterostructures for sodium-ion batteries with high initial coulombic efficiency and cycling stability. ACS Nano 13(3), 3666-3676 (2019). https://doi.org/10.1021/ acsnano.9b00375

26. X. Xiong, G. Wang, Y. Lin, Y. Wang et al., Enhancing sodium ion battery performance by strongly binding nanostructured $\mathrm{Sb}_{2} \mathrm{~S}_{3}$ on sulfur-doped graphene sheets. ACS Nano 10(12), 10953-10959 (2016). https://doi.org/10.1021/acsnano.6b056 53

27. L. Cao, X. Gao, B. Zhang, X. Ou et al., Bimetallic sulfide $\mathrm{Sb}_{2} \mathrm{~S}_{3} @ \mathrm{FeS}_{2}$ hollow nanorods as high-performance anode materials for sodium-ion batteries. ACS Nano 14(3), 36103620 (2020). https://doi.org/10.1021/acsnano.0c00020

28. S. Dong, C. Li, X. Ge, Z. Li et al., ZnS-Sb $\mathrm{S}_{3} @ \mathrm{C}$ core-double shell polyhedron structure derived from metal-organic framework as anodes for high performance sodium ion batteries. ACS Nano 11(6), 6474-6482 (2017). https://doi.org/10.1021/ acsnano.7b03321

29. Y. Huang, X. Hu, J. Li, J. Zhang et al., Rational construction of heterostructured core-shell $\mathrm{Bi}_{2} \mathrm{~S}_{3} @ \mathrm{Co}_{9} \mathrm{~S}_{8}$ complex hollow particles toward high-performance $\mathrm{Li}$ - and $\mathrm{Na}$-ion storage. Energy Storage Mater. 29, 121-130 (2020). https://doi.org/ 10.1016/j.ensm.2020.04.004

30. B. Qu, C. Ma, G. Ji, C. Xu et al., Layered $\mathrm{SnS}_{2}$-reduced graphene oxide composite: a high-capacity, high-rate, and longcycle life sodium-ion battery anode material. Adv. Mater. 26(23), 3854-3859 (2014). https://doi.org/10.1002/adma. 201306314

31. X. Gao, X. Yang, M. Li, Q. Sun et al., Cobalt-doped $\mathrm{SnS}_{2}$ with dual active centers of synergistic absorption-catalysis effect for high-S loading Li-S batteries. Adv. Funct. Mater. 29(8), 1806724 (2019). https://doi.org/10.1002/adfm.201806724

32. M. Hu, H. Zhang, L. Yang, R. Lv, Ultrahigh rate sodium-ion storage of $\mathrm{SnS} / \mathrm{SnS}_{2}$ heterostructures anchored on S-doped reduced graphene oxide by ion-assisted growth. Carbon 143, 21-29 (2019). https://doi.org/10.1016/j.carbon.2018.08.048

33. Y. Xu, W. Cao, Y. Yin, J. Sheng et al., Novel NaTi ${ }_{2}\left(\mathrm{PO}_{4}\right)_{3}$ nanowire clusters as high performance cathodes for mg-na hybrid-ion batteries. Nano Energy 55, 526-533 (2019). https:// doi.org/10.1016/j.nanoen.2018.10.064

34. J. Xie, Y. Zhu, N. Zhuang, X. Li et al., High-concentration ether-based electrolyte boosts the electrochemical performance of $\mathrm{SnS}_{2}$-reduced graphene oxide for K-ion batteries. J. Mater. Chem. A 7(33), 19332-19341 (2019). https://doi.org/ 10.1039/C9TA06418D

35. E.J. Pickering, N.G. Jones, High-entropy alloys: A critical assessment of their founding principles and future prospects. Int. Mater. Rev. 61(3), 183-202 (2016). https://doi.org/10. 1080/09506608.2016.1180020

36. Y. Ma, Y. Ma, Q. Wang, S. Schweidler et al., High-entropy energy materials: Challenges and new opportunities. Energy Environ. Sci. 14, 2883-2905 (2021). https://doi.org/10.1039/ D1EE00505G

37. J. Kim, M.S. Choi, K.H. Shin, M. Kota et al., Rational design of carbon nanomaterials for electrochemical sodium storage and capture. Adv. Mater. 31(34), 1803444 (2019). https://doi.org/10.1002/adma.201803444

38. P. Xiong, P. Bai, A. Li, B. Li et al., Bismuth nanoparticle@carbon composite anodes for ultralong cycle life and high-rate sodium-ion batteries. Adv. Mater. 31(48), 1904771 (2019). https://doi.org/10.1002/adma.201904771

39. C. Li, S. Wang, G. Wang, S. Wang et al., $\mathrm{NH}_{4} \mathrm{~V}_{4} \mathrm{O}_{10} / \mathrm{RGO}$ composite as a high-performance electrode material for hybrid capacitive deionization. Environ. Sci. Wat. Res. 6(2), 303-311 (2020). https://doi.org/10.1039/C9EW00499H

40. L. Shi, D. Li, P. Yao, J. Yu et al., $\mathrm{SnS}_{2}$ nanosheets coating on nanohollow cubic $\mathrm{CoS}_{2} / \mathrm{C}$ for ultralong life and high rate capability half/full sodium-ion batteries. Small 14(41), 1802716 (2018). https://doi.org/10.1002/smll.201802716

41. X. Wang, X. Li, Q. Li, H. Li et al., Improved electrochemical performance based on nanostructured $\mathrm{SnS}_{2} @$ $\mathrm{CoS}_{2}-\mathrm{RGO}$ composite anode for sodium-ion batteries. Nano-Micro Lett. 10(3), 46 (2018). https://doi.org/10.1007/ s40820-018-0200-X

42. X. Liu, Y. Xiang, Q. Li, Q. Zheng et al., $\mathrm{SnS}_{2}-\mathrm{CoS}_{2} @ \mathrm{C}$ nanocubes as high initial coulombic efficiency and long-life anodes for sodium-ion batteries. Electrochim. Acta 387, 138525 (2021). https://doi.org/10.1016/j.electacta.2021.138525

43. P. Nørby, J. Overgaard, P.S. Christensen, B. Richter et al., $\left(\mathrm{NH}_{4}\right)_{4} \mathrm{Sn}_{2} \mathrm{~S}_{6} \cdot 3 \mathrm{H}_{2} \mathrm{O}$ : crystal structure, thermal decomposition, and precursor for textured thin film. Chem. Mater. 26(15), 4494-4504 (2014). https://doi.org/10.1021/cm501681r

44. Z. Hu, L. Wang, K. Zhang, J. Wang et al., $\mathrm{MoS}_{2}$ nanoflowers with expanded interlayers as high-performance anodes for sodium-ion batteries. Angew. Chem. Int. Ed. 53(47), 1279412798 (2014). https://doi.org/10.1002/anie.201407898

45. S. Huang, M. Wang, P. Jia, B. Wang et al., N-graphene motivated $\mathrm{SnO}_{2} @ \mathrm{SnS}_{2}$ heterostructure quantum dots for high performance lithium/sodium storage. Energy Storage Mater. 20, 225-233 (2019). https://doi.org/10.1016/j.ensm.2018.11.024

46. Y. Yang, X.-A. Yang, D. Leng, S.-B. Wang et al., Fabrication of $\mathrm{g}-\mathrm{C}_{3} \mathrm{~N}_{4} / \mathrm{SnS}_{2} / \mathrm{SnO}_{2}$ nanocomposites for promoting photocatalytic reduction of aqueous $\mathrm{Cr}(\mathrm{VI})$ under visible light. Chem. Eng. J. 335, 491-500 (2018). https://doi.org/10.1016/j. cej.2017.10.173

47. S. Wang, F. Gong, S. Yang, J. Liao et al., Graphene oxidetemplate controlled cuboid-shaped high-capacity $\mathrm{VS}_{4}$ nanoparticles as anode for sodium-ion batteries. Adv. Funct. Mater. 28(34), 1801806 (2018). https://doi.org/10.1002/adfm.20180 1806

48. S. Li, P. Ge, F. Jiang, H. Shuai et al., The advance of nickelcobalt-sulfide as ultra-fast/high sodium storage materials: the influences of morphology structure, phase evolution and interface property. Energy Storage Mater. 16, 267-280 (2019). https://doi.org/10.1016/j.ensm.2018.06.006

49. Y. Li, R. Zhang, W. Zhou, X. Wu et al., Hierarchical $\mathrm{MoS}_{2}$ hollow architectures with abundant mo vacancies for efficient sodium storage. ACS Nano 13(5), 5533-5540 (2019). https:// doi.org/10.1021/acsnano.9b00383

50. J. Chen, L. Mohrhusen, G. Ali, S. Li et al., Electrochemical mechanism investigation of $\mathrm{Cu}_{2} \mathrm{MoS}_{4}$ hollow nanospheres for 
fast and stable sodium ion storage. Adv. Funct. Mater. 29(7), 1807753 (2019). https://doi.org/10.1002/adfm.201807753

51. G. Fang, Q. Wang, J. Zhou, Y. Lei et al., Metal organic framework-templated synthesis of bimetallic selenides with rich phase boundaries for sodium-ion storage and oxygen evolution reaction. ACS Nano 13(5), 5635-5645 (2019). https://doi.org/ 10.1021/acsnano.9b00816

52. Z. Ali, T. Tang, X. Huang, Y. Wang et al., Cobalt selenide decorated carbon spheres for excellent cycling performance of sodium ion batteries. Energy Storage Mater. 13, 19-28 (2018). https://doi.org/10.1016/j.ensm.2017.12.014

53. Y. Jiang, G. Zou, H. Hou, J. Li et al., Composition engineering boosts voltage windows for advanced sodium-ion batteries. ACS Nano 13(9), 10787-10797 (2019). https://doi.org/10. 1021/acsnano.9b05614

54. G. Fang, Z. Wu, J. Zhou, C. Zhu et al., Observation of pseudocapacitive effect and fast ion diffusion in bimetallic sulfides as an advanced sodium-ion battery anode. Adv. Energy Mater. 8(19), 1703155 (2018). https://doi.org/10.1002/aenm.20170 3155

55. M. Hadouchi, N. Yaqoob, P. Kaghazchi, M. Tang et al., Fast sodium intercalation in $\mathrm{Na}_{3.41} £_{0.59} \mathrm{FeV}\left(\mathrm{PO}_{4}\right)_{3}$ : a novel sodiumdeficient nasicon cathode for sodium-ion batteries. Energy Storage Mater. 35, 192-202 (2021). https://doi.org/10.1016/j. ensm.2020.11.010

56. J. Zhang, Y. Liu, X. Zhao, L. He et al., A novel NASICONtype $\mathrm{Na}_{4} \mathrm{MnCr}\left(\mathrm{PO}_{4}\right)_{3}$ demonstrating the energy density record of phosphate cathodes for sodium-ion batteries. Adv. Mater. 32(11), 1906348 (2020). https://doi.org/10.1002/adma.20190 6348

57. J. Wang, J. Polleux, J. Lim, B. Dunn, Pseudocapacitive contributions to electrochemical energy storage in $\mathrm{TiO}_{2}$ (anatase) nanoparticles. J. Phys. Chem. C 111(40), 14925-14931 (2007). https://doi.org/10.1021/jp074464w

58. C. An, Y. Yuan, B. Zhang, L. Tang et al., Graphene wrapped $\mathrm{FeSe}_{2}$ nano-microspheres with high pseudocapacitive contribution for enhanced Na-ion storage. Adv. Energy Mater. 9(18), 1900356 (2019). https://doi.org/10.1002/aenm.201900356

59. Y. Tang, X. Li, H. Lv, W. Wang et al., High-energy aqueous magnesium hybrid full batteries enabled by carrier-hosting potential compensation. Angew. Chem. Int. Ed. 133(10), 5503-5512 (2021). https://doi.org/10.1002/anie.202013315

60. X. Liu, K. Zhang, K. Lei, F. Li et al., Facile synthesis and electrochemical sodium storage of $\mathrm{CoS}_{2}$ micro/nano-structures. Nano Res. 9(1), 198-206 (2016). https://doi.org/10.1007/ s12274-016-0981-5

61. K. Zhang, Z. Hu, X. Liu, Z. Tao et al., FeSe $\mathrm{F}_{2}$ microspheres as a high-performance anode material for na-ion batteries. Adv. Mater. 27(21), 3305-3309 (2015). https://doi.org/10.1002/ adma.201500196

62. L. Liang, Y. Xu, C. Wang, L. Wen et al., Large-scale highly ordered sb nanorod array anodes with high capacity and rate capability for sodium-ion batteries. Energy Environ. Sci. 8(10), 2954-2962 (2015). https://doi.org/10.1039/C5EE0 $0878 \mathrm{~F}$

63. P. Xue, N. Wang, Z. Fang, Z. Lu et al., Rayleigh-instabilityinduced bismuth nanorod@ @itrogen-doped carbon nanotubes as a long cycling and high rate anode for sodium-ion batteries. Nano Lett. 19(3), 1998-2004 (2019). https://doi.org/10.1021/ acs.nanolett.8b05189

64. N. Wang, Z. Bai, Y. Qian, J. Yang, Double-walled Sb@ $\mathrm{TiO}_{2-x}$ nanotubes as a superior high-rate and ultralong-lifespan anode material for Na-ion and Li-ion batteries. Adv. Mater. 28(21), 4126-4133 (2016). https://doi.org/10.1002/adma.201505918

65. J. Pan, S. Chen, Q. Fu, Y. Sun et al., Layered-structure sbpo4/ reduced graphene oxide: an advanced anode material for sodium ion batteries. ACS Nano 12(12), 12869-12878 (2018). https://doi.org/10.1021/acsnano.8b08065

66. Q. Gui, D. Ba, Z. Zhao, Y. Mao et al., Synergistic coupling of ether electrolyte and $3 \mathrm{~d}$ electrode enables titanates with extraordinary coulombic efficiency and rate performance for sodium-ion capacitors. Small Methods 3(2), 1800371 (2019). https://doi.org/10.1002/smtd.201800371

67. H. Yuan, F. Ma, X. Wei, J.-L. Lan et al., Ionic-conducting and robust multilayered solid electrolyte interphases for greatly improved rate and cycling capabilities of sodium ion full cells. Adv. Energy Mater. 10(37), 2001418 (2020). https://doi.org/ 10.1002/aenm.202001418 